\title{
ME GUSTA CUANDO GRITAS PORQUE NO ESTÁS AUSENTE... EL SILENCIO Y LA RABIA FEMENINAS A TRAVÉS DE LA LITERATURA UNIVERSAL ${ }^{1}$
}

\author{
Leticia de la Paz de Dios ${ }^{2}$
}

\begin{abstract}
Me gusta cuando gritas porque no estás ausente... el silencio y la rabia femeninas a través de la literatura universal

Resumen: La literatura universal se ha encargado de presentarnos el silencio como un rasgo inherente al sexo femenino. Cuando las mujeres se han atrevido a desafiarlo, han sido consideradas histéricas o locas. La rabia, emoción humana y completamente legítima en un hombre, ha sido interpretada, cuando ha sido femenina, como un ataque a la hegemonía dominante y, por tanto, desacreditada.En este trabajo se pretende desmontar la falacia del silencio como inherentemente femenino y la rabia como legítimamente masculina, y hacer un repaso de aquellas obras de la literatura universal que han servido para bien perpetuar, bien subvertir, dichos conceptos.

Palabras clave: Literatura y género, feminismo, silencio femenino, rabia femenina.
\end{abstract}

I like it when you scream. It is as though you were present... Female silence and anger through world literature.

Abstract: World Literature has represented silence as an inherently feminine feature. When women have dared to challenge it, they have been considered hysterical or crazy. Anger, a human emotion deemed completely legitimate in men, has been interpreted, when it has been feminine, as an attack to the dominating hegemony and, consequently, discredited.

This article aims at dismantling the fallacy of silence as inherently feminine and anger as legitimately masculine, reviewing the works of world literature that have helped perpetuate or subvert said concepts.

Key words: Literature and gender, feminism, female silence, female anger.

\section{Introducción}

Son muchos los estudios que se han realizado sobre la falta de representación femenina en prácticamente todas las esferas -artísticas, sociales, culturales y políticas- y,

\footnotetext{
${ }^{1}$ Fecha de recepción: 11/10/2019.

Fecha de aceptación: 29/11/2019.

${ }^{2}$ Doctoranda en el Programa de Lenguas, Textos y Contextos, Universidad de Granada, España; $\square$ ldelapaz@correo.ugr.es.
} 
sin embargo, aún hoy en día bebemos de una tradición eminentemente masculina que se ha ido perpetuando hasta llegar a nuestros días. La literatura no es una excepción y, a pesar de todos los avances y esfuerzos por rescatar obras de producción femenina, el canon literario está repleto de referentes que, o bien son únicamente masculinos, o bien realizan una descripción plana y estereotipada de la mujer y la feminidad. William Shakespeare, James Joyce, Miguel de Cervantes, Mario Vargas Llosa o Fiódor Dostoyevsky son solo algunos de los nombres que llenan las listas de lectura de las guías docentes a lo largo y ancho del mundo universitario, y son necesarias asignaturas específicas de literatura femenina para que el alumnado conozca que la historia - de la literatura - también ha sido escrita por autoras como Ana Caro, Carmen Martín Gaite, Rosario Castellanos, Audre Lorde o Mary Anne Evan (a la que conocemos por su pseudónimo masculino, George Eliot). La problemática no reside en que leamos a escritores varones, sino en que formemos nuestra conceptualización del mundo teniendo en cuenta el punto de vista de solo una parte de la población y que, además, esta conceptualización esté influenciada por un sistema hegemónico que se ha esforzado por silenciar a la otra mitad. Este trabajo pretende analizar de qué forma se ha representado a la mujer en la literatura universal y cómo dos conceptos - el silencio y la rabia - han sido los hilos conductores para crear esa narrativa tradicional que ha abocado a la mujer a dos destinos con consecuencias igualmente brutales: el de la permanencia - mediante el sometimiento - en el universo narrativo o, por el contrario, el de la expulsión irremediable de él. 


\section{2. ¿Mala mujer?}

Se podría decir que la literatura no ha hecho más que reflejar la desigualdad de género existente en las sociedades que ha ido describiendo, pero no hay que olvidar que este arte (igual que muchos otros) es responsable también de perpetuar esas conceptualizaciones estereotipadas mediante los discursos que se repiten sobre los roles que hombre y mujer deben ocupar en la sociedad.

Sabemos que ha existido y existe un evidente silenciamiento femenino en la literatura universal, consecuencia de las limitaciones que ha sufrido la mujer también en la sociedad. Contamos, por lo tanto, con una tradición literaria que, en primera instancia, apenas ha incluido voces femeninas en el canon literario y que, en segunda (y también como resultado de ello), ha dejado la creación de personajes femeninos en manos de mentes y voces masculinas; es decir, la forma de describir a las mujeres en la literatura a menudo ha respondido a configuraciones u obsesiones masculinas y ha supuesto el reflejo fiel de una ideología patriarcal a la que ha interesado mantener la desigualdad de poder entre hombres y mujeres para asegurar la continuación del sistema androcentrista. TorresPou defiende esta teoría, afirmando que:

los personajes femeninos funcionan como signo del discurso patriarcal, es decir, encarnan conceptos y obsesiones masculinas. Por la misma razón, la función de tales personajes en el texto termina siendo la elaboración de una creación mental previa: la de los mitos que el hombre ha forjado a propósito de la mujer (1998: 14)

De esta forma, la literatura ha presentado a personajes femeninos condenados a aparecer como secundarios, sin matices, supeditados a la existencia de un personaje masculino principal y, en su mayor parte, encasillados dentro de una de las dos 
configuraciones posibles para la mujer dentro de esta perspectiva androcéntrica: la de buena mujer, que se ha ceñido al papel establecido para ella, o la de mala mujer, que se ha rebelado contra el mismo. Esta distinción entre mujer buena o mala no deja de ser una dualidad estereotipada de la figura femenina, una forma de apartar a la periferia a cualquier personaje femenino que se rebele contra lo establecido o que represente algún tipo de riesgo para la estabilidad de los cimientos de una sociedad machista.

Una de las primeras reflexiones sobre la estereotipación de la mujer en la literatura atendiendo a cuestiones puramente de género fue la que realizaron Sandra Gilbert y Susan Gubar en The Madwoman in the attic (1979), obra fundamental en los estudios feministas en literatura para entender la representación de la mujer en la literatura inglesa de la época victoriana. Tras esta obra, la crítica literaria ha seguido reconociendo los diferentes prototipos que han servido para categorizar a la mujer en la literatura y en la historia y ha ido quedando patente cómo, al contrario que los personajes masculinos, los femeninos han sido unidimensionales, y han tendido a ser agrupados de manera dicotómica, abocados, como ya apuntamos, a cumplir sumisamente los roles establecidos en el universo narrativo y simbólico o a ser expulsados del mismo.

La primera dicotomía que nos gustaría destacar coloca frente a esta loca del desván de Gilbert y Gubar al ángel del hogar ${ }^{3}$ y describe a este ángel como a la mujer buena, decente, humilde, sometida a su marido y recluida en el espacio femenino por antonomasia: el hogar. Este personaje no tiene existencia ni fuera de esas cuatro paredes ni independientemente de un personaje masculino protagónico, ya que su única finalidad es ocuparse de las tareas domésticas, de los hijos y del marido. Todo personaje femenino que se ajusta a estas

\footnotetext{
${ }^{3}$ El ángel del hogar, obra publicada en 1859 en España, incidía en un estereotipo descrito ya unos años antes en un poema con el mismo nombre escrito por el inglés Coventry Patmore.
} 
características es considerado virtuoso y, por tanto, se presenta como ejemplo a seguir por las mujeres. En el extremo opuesto aparece el personaje femenino que disrumpe ese orden, que se rebela contra el poder y que no permite ser silenciado. La loca del desván representa a un personaje despreciado, satanizado y a menudo considerado loco, para justificar su aislamiento y su exilio del universo narrativo.

De forma paralela a la anterior, aparece la dicotomía "Nice lady - Bitch" (Lerner 1985: 2), según la cual todo personaje femenino cae irremediablemente en una de estas dos definiciones. Aquel que cumple de forma abnegada con los tres aspectos propios de una buena mujer (ama de casa, esposa fiel y madre amante) será inmediatamente un personaje aceptado dentro del mundo literario dominante creado en la obra. $\mathrm{Su}$ clasificación dentro del grupo de "Nice Ladies" le asegurará un carácter inofensivo y cómodo dentro de la sociedad y del orden patriarcal. Sin embargo, de rebelarse ante dichos aspectos, el personaje catalogado como "Bitch" acabará desapareciendo, habitualmente con un final trágico, para de esta forma poder reestablecer el orden convencional en la narración.

\section{El silencio y la rabia}

Si reflexionamos, aun brevemente, sobre las dicotomías previamente expuestas, es fácil darse cuenta de que ambas - además de muchas otras - han sido configuradas en torno a dos conceptos a los cuales la existencia y la experiencia femeninas han estado íntimamente ligadas: el silencio y la rabia. Estos conceptos han sido dos de los pilares sobre los cuales se 
han construido estos estereotipos femeninos planos y carentes de matices, y silencio y rabia se han constituido como rasgos cuya posesión o carencia ha determinado, de nuevo, la permanencia o la expulsión de estos personajes del universo textual y simbólico de la obra en cuestión.

Centrándonos en primera instancia en el silencio, es fácil afirmar y demostrar que el silencio se ha asociado siempre al género femenino. No nos referimos ya aquí al silencio metafórico, referente a la ausencia de voces femeninas en el arte, la literatura y la política, entre otros, sino al silencio literal como rasgo deseado de una mujer, cuya decencia pasaba también por permanecer en silencio. Las mujeres calladas, sumisas y recatadas han sido un peón para el sistema patriarcal, una forma de imposición y dominación que ha garantizado la continuidad del privilegio social, cultural, político y económico para el hombre.

Como apuntábamos anteriormente, la literatura universal, concepto que hasta muy recientemente se ha referido casi exclusivamente a literatura masculina, ha contribuido a reforzar, perpetuar y adoctrinar con respecto a este papel sumiso que la mujer debía adoptar en la sociedad y así lo han ilustrado obras de literatura de diversas épocas y movimientos literarios. Una de las primeras obras de literatura universal en la que se hace uso ya de la idea de la mujer callada como ideal es la Biblia. Aparece en el libro de Corintios (escrito, según los estudios, entre los años 54 y 57), donde se afirma: "Que las mujeres guarden silencio en las reuniones; no les está, pues, permitido hablar, sino que deben mostrarse recatadas, como manda la ley" (1 Corintios 14:34). En el libro a Timoteo se recurre de nuevo a este concepto, apuntando: “Que la mujer aprenda en silencio con plena sumisión. No consiento que la mujer enseñe ni domine al marido, sino que ha de estar en silencio. Pues primero fue formado Adán, y después Eva" (1 Timoteo 2:11-14). La Biblia insta a sus lectoras a permanecer calladas, sumisas ante el hombre y a no alterar la jerarquía que ordena 
la "Ley". De esta forma, está reclamando a los fieles que sigan ejerciendo lo que Pierre Bourdieu denomina "la dominación masculina" (2000), según la cual el sistema de poder en el mundo se basa precisamente en esa dominación - es decir, en la diferencia biológica y en la supuesta superioridad del hombre sobre la mujer -, pero que esta dominación, que no es más que un constructo creado por la sociedad patriarcal, se extrapola a todos los demás aspectos de la misma, perpetuándose así esta desigualdad de poder.

Podemos imaginar el impacto que las enseñanzas de una obra como la Biblia, la más leída en el mundo, va a tener en el imaginario colectivo universal. Esta imagen pura, casta y virginal que se asocia al silencio traspasa las fronteras temporales, geográficas y sociales y se mantiene hasta nuestros días, donde sigue apareciendo de forma recurrente. Si buscamos más ejemplos de ello en obras de literatura escritas a partir del s. XX, estos siguen siendo numerosos. En la obra canónica de George Bernard Shaw Pygmalion, Mrs. Pearce exige a la protagonista, Eliza Doolittle, que se mantenga callada si quiere ser una buena dama: “MRS PEARCE: Don't answer back, girl! Don't you want to be clean and sweet and decent, like a lady?" (1913: 33). Y esta idea forma parte de nuestros imaginarios de una forma tan profunda, que llega hasta nuestros días, por ejemplo, en uno de los poemas más leídos y recitados en la actualidad en el contexto hispanohablante, representación de un falso mito romántico que relega de nuevo a la mujer a un papel secundario y sumiso: "Me gusta cuando callas porque estás como ausente", empieza el "Poema XV" de los Veinte poemas de amor y una canción desesperada de Pablo Neruda. Vemos cómo en este poema se intenta presentar el silencio no ya como una imposición a la mujer, sino de forma idealizada, sin duda un modo de adoctrinamiento que se ha intentado utilizar de nuevo en textos propagandísticos (literarios o no), como los publicados en España durante el Franquismo. La Sección Femenina de la Falange publica 
en 1958 la Guía de la buena esposa, escrita por Pilar Primo de Rivera, en la que se muestra de nuevo esa idealización del papel de la mujer como ángel del hogar y que supone un intento de concienciación a las mujeres para que asuman los roles que el sistema tradicional patriarcal quiere para ellas. Esta guía incluye extractos como el siguiente: “Todos los días deberíamos de dar gracias a Dios por habernos privado a la mayoría de las mujeres del don de la palabra, porque si lo tuviéramos, quién sabe si caeríamos en la vanidad de exhibirlo en las plazas" (1958: 8).

Paralelamente a estas descripciones del silencio han existido también ejemplos de obras, en su mayoría escritas por mujeres, en las que se ha representado a una mujer que es consciente de esa imposición y que se rebela, o intenta rebelarse, contra ella: "In silence and in secret bled. / No sigh relieved her speechless woe,/ She had no voice to speak her dread" (Taylor Coleridge 1896). Este despertar de las mujeres, o de los personajes femeninos en las obras literarias, ha tenido una consecuencia que se ha descrito en la literatura casi con tanta recurrencia como el silencio: la imposición a las mujeres de mantenerse calladas ha ido acumulando una rabia - lógica - que ha acabado encontrando una vía de escape en los universos textuales de la literatura universal. Sin embargo, las propias convenciones patriarcales, por el temor a que la rabia sacudiera los cimientos de la jerarquía social, han hecho que esta, cuando ha sido femenina, sea inmediatamente deslegitimizada asignándole un carácter de emotividad, infantilismo, histeria o directamente locura.

Cabe ahondar en el tratamiento que se ha hecho de la rabia femenina en contraposición a la masculina. La rabia masculina ha sido considerada legítima y "racional", es decir, nacida de la seguridad del hombre de encontrarse en una situación en la que lleva razón, pero en la que esta se le ha quitado injustamente. Por el contrario, 
la rabia femenina se ha descrito como irracional, pueril, histérica y, por tanto, ha sido ignorada y demonizada a partes iguales. Es tanta la incomodidad que ha causado la rabia femenina, sobre todo cuando ha ido dirigida al hombre, que no solo se ha desacreditado, sino que la mujer que ha expresado rabia se ha considerado loca, histérica, y también poco femenina. La rabia es una emoción que solo debería asociarse al hombre y, consecuentemente, la mujer que la muestra no puede encajar en la sociedad ideal en la que tanto hombre como mujer actúan de acuerdo con los roles dictados para ellos. Artistóteles, en su "Ética a Nicómaco" (s. IV ac) ya predicaba lo siguiente: "The man who is angry at the right things and with the right people, and, further, as he ought, when he ought, and as long as he ought, is praised" (la cursiva es mía) (1980: 73). Cuando Aristóteles habla del hombre no está usando un término genérico, sino que se refiere al individuo de género masculino, y alude al halago que merece aquel (y no aquella) que se enfada con quién debe y por la razón que debe.

Harriet Lerner (autora a la que ya citamos por su descripción de los prototipos de "Bitch" y "Nice Lady") nos ofrece la visión que, por el contrario, se tiene - en la literatura y en la sociedad - de las mujeres que sí muestran su rabia: "The direct expression of anger, especially at men, makes us unladylaike, unfeminine, unmaternal, sexually unattractive or, more recently, 'strident'” (1985: 2). El peligro que conlleva la expresión de la rabia femenina va más allá de un simple alejamiento de la mujer de la femineidad que se espera de ella. Una mujer que expresa su rabia libremente está, de algún modo, comportándose como un hombre y por tanto rebelándose contra un sistema que le niega los mismos derechos que ellos poseen.

La literatura ha sido de nuevo fiel espejo de la realidad en lo que se refiere a la rabia femenina. Ésta ha sido analizada y utilizada de dos formas completamente opuestas: por 
un lado y desde el punto de vista masculino del que hablábamos al comienzo, la rabia femenina se ha interpretado como una transgresión que se ha intentado solventar de diferentes formas: apartando literalmente a esos personajes a los márgenes de la sociedad bajo el pretexto de su locura o mediante la muerte del personaje femenino que desestabilizaba el universo textual masculino (en muchas ocasiones mediante el suicidio, para poder justificar así la inevitabilidad de su muerte y la eximición de la culpa masculina). Independientemente de ello, en todas ha existido un denominador común: la rabia ha provocado un gran asombro en el hombre porque una mujer imponga su rabia, y, tras este primer asombro, una rápida reacción de deslegitimación de la misma. El siguiente ejemplo, extracto de la primera novela de Margaret Atwood, The Edible Woman, ilustra a la perfección dicha reacción masculina ante la rabia de una mujer: "The hot needle of anger in my voice must have penetrated the cuticle of Peter's euphoria. He stepped back a pace; his eyes seemed to measure me coldly." [...] "The trouble with you is,” he said savagely, “you're just rejecting your femininity” (Atwood 1969: 81).

No obstante, desde el punto de vista de la experiencia femenina, la rabia ha supuesto un arma indispensable para luchar conscientemente contra el silenciamiento patriarcal, para subvertir los sistemas convencionales y para alterar el orden natural. Las escritoras han sido conscientes de ello y lo han utilizado como recurso feminista, haciéndolo evidente no solo en los universos simbólicos de sus obras sino como acto consciente de feminismo literario, como ilustra Rosario Ferré cuando declara: "la ira ha sido el incentivo para que muchas mujeres escriban bien" (1976: 9). La ira supone una explosión en la escritura femenina, la oportunidad de transgredir aferrándose a un prototipo (el de la loca en el desván) que se les había impuesto a las mujeres. Éstas crean allí un espacio de resistencia, una venganza contra el hombre (como representante del sistema patriarcal) 
utilizando un recurso, el de la locura y la histeria, creado contra ellas. Como arguye la teórica Lorraine Elena Roses: "La histérica [...] encarna la reminiscencia obstinada del pasado, borra las estructuras establecidas, e introduce y fomenta el desorden" (1993: 282) y continúa: "La histérica es la que llora, se descontrola, se desborda, en su padecimiento se transparenta la realidad de la opresión de la mujer" (1993: 283).

De nuevo encontramos numerosos ejemplos de esta explosión de ira en diferentes obras de la literatura universal. En Puerto Rico, la propia Rosario Ferré utiliza este arma en su colección Papeles de Pandora. Vemos cómo pasa de la consciencia del silencio impuesto en "Eva María" ("He tratado de ser como querías/ buena sorda muda ciega" (1976: 17)) a la rabia en "La bailarina": "te levantaste gritando no puedo/ [...]/ arrastrando tu ira por todas las calles/ gritando aunque me duela y el niño llore yo bailo" (1976: 142), y continúa admitiendo el peso que supone contener la rabia y asumir el silencio ("Tantos años de rabia atarascada en la garganta como un taco mal clavado, Ambrosio" (1976: 30)) para la experiencia femenina. En EE.UU., la poeta Adrienne Rich también usa la rabia como fuente creadora en su poema "The Stranger": "my visionary anger cleansing my sight/and the detailed perceptions of mercy/flowering from that anger" (1973), reconociendo el carácter revulsivo de la rabia y haciéndola responsable de su despertar y de su reconocimiento de la situación de opresión en la que se encuentra como mujer.

\section{Conclusión}

Como advierte la poeta estadounidense Audre Lorde en el título de su obra Your silence will not protect you (2017), vuestro silencio no os protegerá. Con estas palabras, 
Lorde ha querido advertir a las mujeres, animarlas a levantar la voz y prevenirlas ante el peligro que seguir calladas puede suponer no solo para ellas, sino para toda la sociedad. En este momento en el que los feminismos han logrado sacudir conciencias, establecerse como movimientos imparables que alcanzan todos los ámbitos políticos, laborales, culturales y sociales (desde el \#metoo al "Hermana, yo sí te creo", pasando por las multitudinarias marchas del 8 de marzo a lo largo y ancho del mundo occidental), es esencial aprovechar el impulso y negarse a dar un paso atrás. Pero mirar hacia adelante pasa también por reconsiderar los discursos con los que hemos crecido y en los que se nos ha educado, "recolectar nuestros relatos y a la vez aprender a releer los relatos de los hombres con los que nuestra mirada y nuestra voz han sido alfabetizadas" (Sanz 2018:17).

Este trabajo ha señalado solo algunas de las formas en las que la literatura ha contribuido a la continuación de unas imágenes y concepciones de los hombres y, sobre todo, de las mujeres, basadas en estereotipos sexistas. Recuperar y rescatar a figuras femeninas que han sido silenciadas es indispensable para construir discursos con los que subvertir el silenciamiento y la estereotipación a través de la literatura, y así conseguir que las futuras generaciones cuenten con un abanico de referentes en los que todas las ideologías, voces, experiencias y géneros tengan una representación justa e igualitaria.

\section{Referencias bibliográficas}

Aristotle. 1999. Nicomachean Ethics. Londres: Pearson.

Atwood, Margaret. 1969. The Edible Woman. Nueva York: Anchor Books. 
Bernard Shaw, George. 1913. Pygmalion. Essex: Longman Literature.

Bourdieu, Pierre. 1998. La dominación masculina. Barcelona: Anagrama.

Coleridge, Mary Elizabeth. 2000. "The Other Side of a Mirror." The Norton Anthology of English Literature. Seventh Edition, Volume 2. Ed. M.H. Adams. Nueva York, Londres: W. W. Norton \& Company.

Ferré, Rosario. 1976. Papeles de Pandora. Nueva York: Vintage Books.

Gilbert, Sandra M. y Susan Gubar. 1979. The Madwoman in the Attic: The Woman Writer and the Nineteenth-century Literacy Imagination. New Haven: Yale University Press.

Lerner, Harriet. 1985. “The Challenge of Anger”. Dance of Anger: A Woman's Guide to Changing The Patterns of Intimate Relationships". Nueva York: Harper Collins.

Lorde, Audre. 2017. Your Silence will not Protect You. Londres: Silver Press.

Neruda, Pablo. 1924. Veinte poemas de amor y una canción desesperada. Santiago: Editorial Nascimento.

Primo de Rivera, Pilar. 1958. Guía de la buena esposa. Madrid: Sección Femenina de la Falange.

Rich, Adrienne. 1973. Diving into the Wreck. Poems 1971-1972. Nueva York: W. W. Norton \& Company.

Roses, Lorraine Elena. 1993. "Las esperanzas de Pandora: Prototipos femeninos en la obra de Rosario Ferré”. Revista Iberoamericana 59: 279-287.

Sanz, Marta. 2018. Monstruas y centauras. Nuevos lenguajes del feminismo. Barcelona: Editorial Anagrama.

Sinués, María del Pilar. 1881. El ángel del hogar. Estudio. Tomo primero. Madrid: Librerías de A. de San Martín.

Torres-Pou, Joan. 1998. El E(x)terno Femenino: Aspectos de la representación de la mujer en la literatura Latinoamericana del siglo XIX. Barcelona: PPU. 